\title{
INTERVENIR EN TIEMPOS DE PANDEMIA. ADAPTACIONES METODOLÓGICAS Y CONDICIONES LABORALES EN EL "PROGRAMA FAMILIAS"
}

\section{InTERVENE In TIMES OF PANDEMiC. Methodological AdAPTATIONS AND WORKING CONDITIONS IN THE "PROGRAMA FAMILIAS"}

Fecha recepción: 18 de abril de 2021 / fecha aceptación: 21 de mayo de 2021

\section{Inti Fernando Fuica Rebolledo ${ }^{1}$}

Cómo citar este artículo:

Fuica Rebolledo, I. (2021) Intervenir en tiempos de pandemia. Adaptaciones metodológicas y condiciones laborales en el "Programa Familias". Revista Pensamiento y Acción Interdisciplinaria, 7(1), 11-31. http://doi.org/10.29035/pai.7.1.11

\section{Resumen}

El programa Familias es la política pública de lucha contra la pobreza más importante del Estado chileno. El acompañamiento psicosocial y sociolaboral por parte de las Apoyos Familiares Integrales es parte crucial de su metodología de intervención, a partir de visitas a los hogares de las familias usuarias. Debido a la crisis desatada por la pandemia de COVID19, el acompañamiento presencial debió ser modificado por un acompañamiento telefónico, en un esfuerzo de adaptación metodológica que busca dar continuidad a la intervención del programa Familias. Así también, la emergencia sanitaria evidenció las complejas condiciones laborales en las que trabajan las profesionales encargadas de esta intervención y la fragilidad de las estrategias gubernamentales para la superación de la pobreza. A partir del análisis de 31 entrevistas realizadas a profesionales que trabajan en esta política pública a nivel municipal, durante los primeros meses de pandemia, exploramos las consecuencias de la adaptación metodológica, sus limitaciones y los efectos del teletrabajo sobre las Apoyos Familiares Integrales y sobre la propia intervención.

Palabras clave: Adaptación metodológica; condiciones laborales; COVID19; Estado; intervención.

1 Sociólogo, Máster en Antropología: Investigación avanzada e intervención social. Estudiante del Doctorado en Antropología Social y Cultural de la Universitat Autònoma de Barcelona, España.

Correo electrónico: inti.fuica.rebolledo@gmail.com. ORCID: https://orcid.org/0000-0002-2089-5062 


\begin{abstract}
The programa Familias is the most important public policy to combat poverty in the Chilean State. The psychosocial and socio-labor accompaniment by the Apoyos Familiares Integrales is a crucial part of their intervention methodology, based on visits to the homes of the user families. Due to the crisis unleashed by the COVID19 pandemic, the face to face accompaniment had to be modified by a telephone accompaniment, in a methodological adaptation effort that seeks to give continuity to the intervention of the programa Familias. Likewise, the health emergency evidenced the challenging working conditions in which the professionals in charge of this intervention work and the fragility of government strategies to overcome poverty. Based on the analysis of 31 interviews carried out whit professionals who work in this public policy at the municipal level, during the first months of the pandemic, we explore the consequences of the methodological adaptation, its limitations, and the effects of teleworking on the Apoyos Familiares Integrales and on the intervention itself.
\end{abstract}

Keywords: COVID19; intervention; methodological adaptation; State; working conditions.

\title{
Introducción
}

El presente artículo presenta un fragmento de los resultados de investigación de la tesis doctoral del autor. Ésta se enfoca en el programa Familias (PF), como la política pública que el Estado de Chile destina al mejoramiento de las condiciones vitales, materiales y comunitarias de la población más pobre y vulnerable del país. En este marco, se realiza una exposición de algunas consecuencias de la pandemia de COVID19 sobre su modelo de intervención y las condiciones laborales de las profesionales que trabajan en los equipos municipales encargados de la interacción cotidiana con las familias usuarias, Ilamadas Apoyos Familiares Integrales (AFI).

En primer lugar, se exponen brevemente algunos lineamientos teóricos que organizan la investigación, así como antecedentes relevantes respecto de la historia del programa Familias. En segunda instancia, se describen los aspectos metodológicos que permitieron el levantamiento de los datos y su posterior análisis. El tercer apartado corresponde a una descripción de las consecuencias de la crisis sanitaria sobre la intervención del programa Familias, vertebrada a partir de los relatos de sus propias protagonistas, en donde se destacan las adaptaciones metodológicas, las condiciones laborales y las iniciativas que las profesionales llevan adelante para enfrentar la pandemia desde su espacio laboral. Para concluir, se presenta una lectura estructural del fenómeno descrito, ya que éste evidencia importantes aspectos del quehacer estatal en Chile. 


\section{Marco referencial}

En una definición tradicional, las políticas públicas son consideradas como procesos de tomas de decisión y acción por parte de las autoridades para intervenir sobre alguna situación que se ha definido como un problema público, con la finalidad de generar impactos considerados positivos, a través de agencias públicas que implementan, financian o gestionan estas acciones (Olavarría, 2007; Velásquez, 2009). Sin embargo, si analizamos el rol que juegan respecto a modelar comportamientos y construir identidades colectivas (Ramírez, 2010; Shore, 2010; Shore \& Wright, 1997), podemos afirmar que también corresponden a tecnologías de gobierno, en el sentido desarrollado por Foucault (1990, 2008, 2009)². Por el mismo proceso de definir una intervención para solucionar algún problema público, las políticas públicas constituyen vectores explícitos de la gubernamentalidad ${ }^{3}$ estatal, ya que, tanto en sus fundamentos como en sus acciones cotidianas, se evidencian los lineamientos ideológicos que sostienen el accionar estatal, permitiendo pesquisar directamente los procesos de (re) producción del Estado a través de sus prácticas (Gupta, 2015; Okongwu \& Mencher, 2000; Restrepo, 2010; Shore, 2010). Considerando estos lineamientos teóricos, este tipo de políticas públicas resultan especialmente interesantes, ya que representan aquellos mecanismos que el Estado acciona para hacerse cargo de los más vulnerables de la sociedad (Rojas, 2019).

Desde 2016, el programa Familias es la principal política pública dirigida a la población más vulnerable de Chile, heredera del programa Puente. Con una cobertura cercana a las 45.000 familias anuales distribuidas en todas las comunas del territorio nacional, su relevancia es innegable. Destinada a las familias consideradas en situación de extrema pobreza y vulnerabilidad, su principal objetivo es contribuir a que las familias superen esta situación mediante una intervención de dos años cuya metodología de trabajo consta de tres componentes principales: Acompañamiento psicosocial y sociolaboral; transferencias monetarias (condicionadas y no condicionadas); acceso preferente a la oferta programática estatal (Ministerio de Desarrollo Social, 2017). Forma parte del subsistema Seguridades y Oportunidades, que comprende a otros tres programas dirigidos a diferentes poblaciones definidas como prioritarias por el Estado: Vínculos, para adultos mayores; Calle, para personas en situación de calle; Abriendo Caminos, destinado a menores de edad con un adulto significativo privado de libertad (Ministerio de Desarrollo Social, 2017).

2 Las tecnologías de gobierno o mecanismos de seguridad, son dispositivos complejos mediante los cuales los Estados buscan gobernar a las poblaciones. Esto es, dirigirles hacia los objetivos definidos como prioritarios por el Estado, no mediante la coerción directa, sino que buscando que los objetivos de la población coincidan con los del Estado (CastroGómez, 2010; Foucault, 1990, 2008, 2009).

3 La gubernamentalidad es considerada por Foucault como una grilla de inteligibilidad, concepto utilizado para describir aquellos dispositivos que buscan gobernar las conductas de las personas introyectando los objetivos. En este caso, me refiero a gubernamentalidad en su definición estrecha, ya que la asocio directamente con tecnologías de gobierno estatales (Irusta, 2014). Sin embargo, el concepto de gubernamentalidad puede ser utilizado para diferentes iniciativas de gobierno que pueden escapar al accionar estatal (Rose \& Miller, 1992). 
El programa Familias corresponde a la última reformulación metodológica de la política pública dirigida a las familias en condición de extrema vulnerabilidad. Es heredera directa del Ingreso Ético Familiar, que corresponde a su vez a la modificación legal ocurrida en el año 2012, en donde el anterior subsistema Chile Solidario y su programa insignia Puente pasaron a ser absorbidos por el nuevo subsistema Seguridades y Oportunidades (Ley 20.595, 2012). A pesar de los cambios de nombre y de prioridades en términos de resultados esperados, el modelo de gestión institucional y de intervención profesional se ha mantenido estable desde el año 2002, cuando bajo el gobierno de Lagos se institucionalizó el programa Puente (Larrañaga et al., 2014; Rojas, 2019). En este caso, la institución que supervisa todo el subsistema es el ministerio de Desarrollo Social (MDS), pero aquella que se encarga de velar por la correcta implementación metodológica del programa Familias es el Fondo Solidario de Inversión Social (FOSIS). Es también FOSIS la institución que firma el convenio con las municipalidades, en donde las últimas se encargan de la contratación de las profesionales que llevan adelante la intervención y de proveer un espacio físico para el funcionamiento del equipo. Por su parte, FOSIS entrega recursos, materiales y la asesoría técnico-metodológica que asegura la calidad de la intervención.

En este artículo se entenderá por "metodología" del programa Familias al diseño de intervención determinado por el Departamento de Diseño Metodológico del ministerio de Desarrollo Social. Sus objetivos son reducir la brecha existente en el ejercicio de derechos; el fortalecimiento de las capacidades individuales, familiares y comunitarias; lograr la inserción laboral (Ministerio de Desarrollo Social, 2016). Se basa en una matriz de bienestar, que incorpora un diagnóstico respecto a través de indicadores de las condiciones de bienestar en 5 dimensiones: Educación; Salud; Vivienda y Entorno; Trabajo y Seguridad Social; Ingresos, a las que se suma de forma transversal la dimensión de Apoyo y Participación Social (Ministerio de Desarrollo Social, 2016). El componente de acompañamiento es el principal mecanismo de intervención para mejorar estas condiciones de bienestar ${ }^{4}$, siendo definido por el ministerio como sigue:

el Acompañamiento como metodología de trabajo del Programa Familias consiste en apoyar, activar y facilitar procesos dirigidos para alcanzar logros básicos de bienestar, promoviendo el fortalecimiento y desarrollo de habilidades sociales y competencias de empleabilidad, la relación con las redes institucionales y comunitarias, partiendo de las necesidades y recursos presentes en la familia y entorno para alcanzar logros básicos de bienestar, en lo cual también contribuye la existencia de bonos y transferencias monetarias que permiten aumentar ingresos por un periodo de tiempo (Ministerio de Desarrollo Social, 2016, p. 23).

\footnotetext{
4 Para mayores detalles revisar el Informe de Desarrollo Social (Ministerio de Desarrollo Social, 2017), o la propia ley que crea el subsistema Seguridades y Oportunidades (Ley 20.595, 2012).
} 
Este formato de relación establecida entre el Estado y la población más vulnerable ha sido denominado como lo social asistencializado, ya que, si bien es el Estado quien se encarga masivamente de la vulnerabilidad, lo hace retomando los principios básicos de la acción asistencial-proximidad, voluntad de quien asiste y establecimiento de una relación directa- en las políticas contemporáneas (Rojas, 2019). De ahí que podamos establecer a esta política pública como heredera de la larga tradición de intervención social instaurada a inicios del siglo XX por medio de las visitadoras sociales (Illanes, 2007).

En la relación establecida entre Estado y población extremadamente vulnerable, las principales mediadoras, en el sentido otorgado por Latour (2008)5, son las Apoyos Familiares Integrales. Éstas son las profesionales encargadas de llevar adelante la intervención cotidiana, a partir del componente de acompañamientos psicosocial y sociolaboral, asistiendo a los domicilios de las familias usuarias para realizar la intervención (Larrañaga et al., 2014; Rojas, 2019). Por intervención, se entiende el proceso mediante el cual estas profesionales escuchan, orientan y transmiten conocimiento a las familias usuarias. Tiene una duración de dos años y consta de un máximo de 32 sesiones $^{6}$, cada una de las cuales tiene un objetivo y una forma de trabajo determinada por la metodología del programa. La descripción del perfil del cargo AFI es bastante amplia, respondiendo usualmente a profesionales provenientes de la difusa área social, sin embargo, en su mayoría se trata de trabajadoras o asistentes sociales, y más de un $88 \%$ de género femenino, de acuerdo con una encuesta realizada durante 2014 (Larrañaga et al., 2014)7. A partir del año 2016, con la reformulación metodológica que rige al actual PF, se incorpora la labor de Gestión Sociocomunitaria (GSC), en donde una o varias AFI se encargan de la realización de sesiones grupales y comunitarias, con la finalidad de fomentar la vinculación en red con organizaciones comunitarias locales e instituciones públicas y privadas (Ministerio de Desarrollo Social, 2017). De acuerdo con diferentes evaluaciones, y lo relevado durante esta investigación, el aspecto mejor valorado de la intervención del programa Familias es el vínculo directo, personal y cara a cara, que se establece entre las familias y las Apoyos Familiares Integrales (Galasso, 2011; Larrañaga et al., 2014; Rojas, 2019; Vega, 2011).

Con el advenimiento de la pandemia por COVID19 y las consecuentes medidas sanitarias para contener su propagación, los acompañamientos psicosocial y sociolaboral debieron ser completamente reformulados. El formato de intervención, vigente desde el año 2002, ya no podía realizarse con la tradicional

\footnotetext{
5 Para Bruno Latour (2008), los actores mediadores son aquellos que tienen un rol activo y creativo al asociarse con otros actores. Por contraparte, los actores intermediarios tienen un rol pasivo y sólo transmiten la información. Dada la naturaleza del trabajo de las AFI, es innegable que son actores activos en la producción del programa Familias, ya que deben adaptarse a diferentes situaciones y aportan un valor propio a la intervención.

6 El acompañamiento psicosocial, al cual ingresan todas las familias usuarias del programa Familias, consta de 15 sesiones familiares y 8 sesiones grupales. El acompañamiento sociolaboral, cuya aplicación depende de las necesidades y posibilidades del grupo familiar que se determinan en la sesión diagnóstica, consta de 5 sesiones individuales y 4 sesiones grupales.

7 En el trabajo de campo de la investigación, la mayoría de las AFI y GSC eran efectivamente trabajadoras sociales. Sin embargo, también se realizaron entrevistas a profesionales formados en Sociología, Antropología, Periodismo e Ingeniería Comercial.
} 
visita domiciliaria por parte de la AFI, ya que esta modalidad pone en riesgo de contagio tanto a las familias usuarias como a las profesionales. Expondremos los efectos de estos cambios sobre la metodología de intervención y las consecuencias en las condiciones laborales de las Apoyos Familiares Integrales en este artículo.

\section{Metodología}

El enfoque metodológico de la investigación que da origen a los hallazgos presentados en este artículo se enmarca dentro de la tradición cualitativa, comprensiva e interpretativa de las ciencias sociales (Díaz de Rada, 2011; Ruiz, 2007). El diseño de investigación es de carácter etnográfico, a partir de la combinación de análisis de documentos secundarios, observación participante y realización de entrevistas a actores clave, como una forma de realizar etnografía del Estado a partir de la antropología de las políticas públicas (Fuica \& Carrasco, 2021; Gupta, 2015; Shore, 2010). El trabajo de campo se dividió en dos fases. La primera se realizó entre los meses de abril y noviembre de 2018, enfocada en el ministerio de Desarrollo Social y FOSIS. La segunda fase del trabajo de campo enfatizaba la observación participante, por lo que se acordó realizar un seguimiento a un equipo del programa Familias entre los meses de marzo y junio de 2020, con la finalidad de dar cuenta de las prácticas cotidianas que permiten la (re)producción del Estado, a partir de la coparticipación del investigador (Díaz de Rada, 2011) $)^{8}$. Sin embargo, el estado de emergencia decretado en marzo de 2020 obligó a suspender esta técnica de investigación, ya que resultaba imposible de realizar dadas las condiciones sanitarias y sus consecuencias sobre la propia labor de los equipos municipales del PF.

A partir de esta situación, el trabajo de campo sufrió una reformulación metodológica, lo que llevó a suspender la observación participante y trocarla por la realización de entrevistas semiestructuradas a las profesionales que conforman el equipo municipal del PF. Utilizando criterios de muestreo teórico, centrados en la experiencia cotidiana en la intervención propia del programa Familias, se definió como sujetos de investigación a las AFI y GSC que se encontrasen trabajando en el programa Familias a nivel nacional. En primera instancia, las entrevistas se realizaron al equipo municipal que había aceptado la presencia del investigador para la realización de observación participante, aumentando luego el número de informantes a partir de la técnica de bola de nieve, hasta alcanzar un nivel de saturación teórica suficiente para asegurar la confiabilidad de los datos producidos (Ruiz, 2007). La técnica utilizada para la recolección de información fue la entrevista semiestructurada, ya que ésta posibilita la indagación en las temáticas definidas por el investigador-aquellas que se esperaban indagar mediante la observación directa de las práctica-, pero también entrega libertad a las entrevistadas para construir su propio relato, recabando aspectos emergentes de su labor cotidiana que podían

8 Para una explicación en profundidad de los aspectos teórico-metodológicos del diseño de investigación ver (Fuica \& Carrasco, 2021). 
no haber sido previstas en la pauta de entrevista (Ballestín \& Fàbregues, 2018, Díaz de Rada, 2011, Ruiz, 2007). Uno de estos elementos emergentes y no previstos fueron las adaptaciones contingentes al contexto de la emergencia sanitaria, así como su impacto sobre la intervención y las condiciones laborales de las AFI, cuyos hallazgos estructuran el presente análisis.

Se totalizó una muestra de 31 entrevistas, realizadas durante los meses de marzo a junio de 2020. Las AFI y GSC entrevistadas provenían de 12 equipos municipales de 5 regiones diferentes del país. Hay que tomar en consideración que las entrevistas fueron realizadas durante los primeros meses de pandemia, por lo que se recabó in situ las diferentes adaptaciones y decisiones que se fueron tomando para sostener la intervención. Es probable que con posterioridad estas medidas hayan sido modificadas, ya sea a partir de la propia experiencia acumulada sobre el teletrabajo, los cambios en las directrices gubernamentales respecto al trabajo a nivel municipal o el nuevo conocimiento respecto del manejo sanitario del virus SARS-COV-2. Sin embargo, resulta interesante presentar cómo vivieron los equipos municipales estas tensiones durante los primeros 4 meses de crisis sanitaria. Para el análisis de la información, se utilizó la técnica de análisis de contenido con perspectiva crítica (Ruiz, 2007, Van Dijk, 2003, Wodak, 2003), siempre respetando el discurso propio de las informantes, las verdaderas expertas respecto de su labor profesional (Latour, 2008). El análisis crítico del discurso distingue tres niveles de análisis: el textual, contextual e interpretativo. El análisis consiste en un constante ir y venir entre estos niveles, codificando el nivel textual para generar categorías cada vez más generales que dan cuenta del nivel contextual, para finalmente realizar una vinculación con los elementos teóricos que dan pie a salidas interpretativas. En este escrito, nos concentramos en el aspecto contextual descriptivo, para realizar un análisis interpretativo de las condiciones laborales de las AFI y las adaptaciones contingentes a la situación pandémica. Los resultados fueron validados mediante los criterios de credibilidad y confirmabilidad (Castillo \& Vásquez, 2003, Ruiz, 2007).

\section{Resultados}

Uno de los aspectos más interesantes de los hallazgos emergentes de la investigación, fueron las diferentes adaptaciones metodológicas y cambios laborales que se produjeron en el trabajo del programa Familias, a raíz de la pandemia de COVID-19. Desde la reformulación metodológica de 2016, los y las Gestoras Sociocomunitarias cumplen con la labor de realizar talleres grupales y comunitarios con las familias usuarias del programa Familias, pero además se encargan de mantener actualizado el conocimiento en torno a las redes de programas e instituciones con las que se puede vincular el programa Familias en cada comuna. Esto les lleva a tener un trabajo más cercano a la Jefa de Unidad de Intervención Familiar (JUIF), empleada municipal que supervisa la implementación del PF en cada comuna. Esto acarrea 
que las profesionales que cumplen la labor de GSC, muchas veces subrogan a las JUIF cuando éstas están cumpliendo otras labores:

\begin{abstract}
"me tocó como algo nuevo porque, no sé si está bien dentro de la metodología, pero era como un, eh, aportar eh... en lo que es estar al tanto de todo lo que es reuniones. Por ejemplo, todas las reuniones de los programas que postulamos nosotros, y todos los colegas a las personas, de FOSIS, estar en las reuniones, hacer distintas coordinaciones, y eso me ayudó a mí, claro, a tener más conocimiento sobre los distintos programas [...] cuando la jefa no puede, asisto yo" (Entrevista 11, GSC, municipalidad urbana)
\end{abstract}

Esta situación se vio exacerbada por la pandemia de COVID-19, ya que muchas de las GSC, en particular aquellas provenientes de las comunas más pequeñas -en donde el cargo de JUIF suele corresponderse con la Dirección de Desarrollo Comunitario-, tuvieron que liderar la adaptación contingente del equipo municipal del programa Familias a las condiciones de emergencia sanitaria:

"También me ha tocado un poquito articular y ser como, como un, tomar un poco el mando podría decirse, como asumir un poco el rol del jefe de unidad en este momento, porque la DIDECO que es nuestra jefa, está ahí con la pega de la emergencia sanitaria cien por ciento. Entonces mucho tiempo para dedicarle al programa o saber cómo estamos, si estamos bien o estamos mal, si estamos haciendo la pega o no, en verdad no, no hay" (Entrevista 28, GSC, municipalidad rural)

Con la suspensión de la realización de talleres ante la emergencia sanitaria, la labor de las Gestoras Sociocomunitarias se vio seriamente reducida. Ante esto, especialmente en los casos en que había dedicación exclusiva a la gestión sociocomunitaria9 ${ }^{-}$, las GSC asumieron el rol de centralizar la información atingente a la pandemia que circulaba por los medios de comunicación, ejerciendo en la práctica una labor de coordinación respecto del resto del equipo:

"me ha tocado un poquito articular esa información, desgranar un poco la información que anda dando vuelta, que sale en la televisión, para también, para que todos manejemos la misma información ¿ya? porque en equipos grandes igual es, cada uno puede entender las cosas de manera diferente ¿ya? por lo menos antes, cuando nos veíamos en la oficina, si alguien tenía una duda, preguntaba. Preguntaba '¿saben qué chiquillos? ¿de qué se trata este bono? ¿estaré bien o no?’ Entonces ahora, claro, por whatsapp, pero muchas veces... Por eso tratamos

9 Recordemos que en algunas comunas la gestión sociocomunitaria se reparte entre distintas AFI. 
de mantener las reuniones una vez a la semana y yo me he encargado de hacer reportes semanales. O sea de, como te digo de, sintetizar, sistematizar un poquito la información, dejarlo lo más claro y lo más sencillo posible y socializarlo con todos los colegas" (Entrevista 28, GSC, municipalidad rural)

Para el caso de las Apoyos Familiares Integrales, la realización de las visitas domiciliarias para cumplir con los acompañamientos psicosocial y sociolaboral también se suspendieron. A medida que avanzaban los meses de pandemia, lo relatado respecto de su trabajo iba también cambiando. En las primeras entrevistas las profesionales solo sabían que ahora debían teletrabajar desde sus hogares, intentando evitar así aumentar el ritmo de contagios por el nuevo virus, aunque pocas semanas después esta se transformó en la directriz oficial emanada desde FOSIS:

"Estábamos trabajando hasta la fecha que nos enviaron a todos después para los, los domicilios. Porque como te decía, corríamos mucho riesgo en el tema de que, al menos yo, por lo menos yo trabajo harto en terreno. Entonces igual estamos expuestas a, no sé poh, pegarnos algún bicho, frío, lo que sea. Sobre todo porque trabajamos harto con familias que son, eh, vulnerables, y que son de, con enfermedades crónicas bien complejas. Así es que, luego de eso, decidieron enviarnos a la mayoría de todos los funcionarios a los domicilios, y trabajamos desde la casa" (Entrevista 06, AFI, municipalidad urbana)

Una de las primeras medidas que adoptaron los equipos municipales del programa Familias fue, una vez establecido el teletrabajo, mantener el contacto con las familias usuarias a través de whatsapp o de llamadas telefónicas. A partir de estos contactos, las profesionales informaban de las primeras medidas de contingencia que adoptaba el gobierno:

"A ver, nosotros ¿ya? acordamos con los jefes de unidades, mantener el contacto con las familias, a través, vía telefónica, mensaje por whatsapp ¿ya? primero, informando sobre los cuidados necesarios $p a^{\prime}$ evitar el, la pandemia, eh... un diagnóstico, bien a grandes rasgos, de su situación. Por ejemplo, que si existen o no cesante dentro del grupo familiar. Algunos requerimientos que necesitan, información por ejemplo de algún beneficio que se va a entregar. Como el bono coronavirus. Que se entregan 50.000 pesos por carga familiar y por ser del programa ¿ya? entonces digamos que se hace una, un pequeño diagnóstico y pequeña entrega de información, en relación a 
cada una de las familias dentro del Programa" (Entrevista 03, AFI, municipalidad urbana)

La realidad de las familias usuarias del PF, que corresponden a la franja más vulnerable de la población en Chile, se vio severamente afectada por la crisis sanitaria. Sus condiciones de vida, de partida complejas, se vieron recrudecidas, enfrentándose a la pérdida de sus fuentes laborales o de ingreso, sin acceso a ahorros y con baja previsión social. Estas difíciles situaciones interpelaban directamente a las profesionales del programa Familias, quienes se veían impotentes frente a la posibilidad de mejorar su situación, ya que a través de los llamados telefónicos lo único que podían hacer era recabar información y derivar a otros departamentos municipales:

\begin{abstract}
"netamente son llamados telefónicos, y envío de personas con situación precaria para ayuda social. Que lo tiene el ministerio. Porque nosotros no podemos hacer nada, solamente informar que esta señora necesita una caja de alimentos, porque fue despedida. O está cesante, y no puede salir porque cuida a su mamá adulta mayor. Entonces ahí tenemos que ver registro, si lo hacen o no lo hacen. Porque una cosa es que uno lo haga, pero otra cosa que la municipalidad entregue el beneficio" (Entrevista 04, AFI, municipalidad urbana)
\end{abstract}

En términos profesionales, el desafío para las AFI fue muy relevante. No solo porque tuvieron que adaptarse a un formato laboral nuevo como el teletrabajo, sino que enfrentaron un importante aumento de su carga laboral. Esto porque la atención telefónica de las familias usuarias difuminó los límites horarios, asimismo, la real situación de emergencia que enfrentaban muchas de estas familias, hacía imperativa una pronta respuesta por parte de las profesionales:

"en la situación actual que estamos, eh, tiende a... a, a estar como uno conectado al 100\%. A las finales uno ahora, actualmente, está trabajando más que lo que trabajaba antes. Porque las familias te mandan en cualquier momento, te hacen consultas en cualquier momento, fuera de horario. Es muy dificil poder determinar, uno igual tiene que estar pendiente de la situación porque el contexto también lo amerita" (Entrevista 13, AFI, municipalidad rural)

El giro radical que experimentó la metodología del programa Familias, al suspenderse la intervención cara a cara, y la incapacidad de gestionar directamente ayudas hacia las familias que las requerían, aumentó de sobremanera la presión hacia las Apoyos Familiares Integrales. A medida que pasaban las semanas, FOSIS comenzó a emanar directrices metodológicas que buscaban sostener la 
intervención de forma remota, con la finalidad de no perder totalmente el eje de trabajo del PF:

"nos llegó una orientación, bastante atrasada diría yo, pero me imagino también porque ellos estaban trabajando en eso que es nuevo para todos. Eh, nos llegó una orientación sobre la modalidad de las llamadas telefónicas. Sobre cómo, qué tipo de contenidos tenían que tener, bueno siempre basado en esta matriz de bienestar, que me imagino que tú bien la conoces, con estas 5 dimensiones. Entonces como orientar un poco cómo orientar esto del llamado telefónico. Eso es lo que hemos recibido de FOSIS y en términos de orientaciones" (Entrevista 20, AFI, municipalidad urbana)

Sin embargo, para las profesionales municipales no fue sencillo acatar este mandato, ya que los requisitos de la intervención no se correspondían con las prioridades de las familias en un contexto de pandemia:

"creo que volvimos un poco al inicio, al génesis muchas veces de la intervención. Porque ahora estamos trabajando en base a la emergencia. Entonces, nosotros, por ahora estamos con teletrabajo, y no estamos con sesiones propiamente tal del programa. Creo que es imposible, yo la verdad, también el otro día lo conversaba con mi Apoyo [Provincial] ${ }^{10}$ y le decía 'yo me rehúso a tomar el teléfono y llamar a una familia para preguntar si se inscribió o no en un curso, porque creo que por ahora no es relevante'. O sea, las personas ahora tienen preocupaciones que son, si van a comer, de cómo están los niños pudiendo hacer las tareas a través de sus casas, si van a poder acceder o no a algún tipo de transferencia nueva que se esté avisando, algún bono, algún subsidio nuevo. Entonces, más que nada, tiene que ver con acercar la oferta, y además con hacer contención. Yo creo que ese es como el principal foco que tenemos nosotros ahora a través de nuestro trabajo" (Entrevista 19, AFI, municipalidad urbana)

Las profesionales municipales comentaron que, en los casos que correspondía, se intentaba seguir con la intervención siguiendo los lineamientos de FOSIS. EI problema reiterativo, es que las familias no se encontraban interesadas en los aspectos propios del programa Familias, sino que la conversación derivaba hacia la búsqueda de contención por parte de la profesional y la solicitud de gestionar

10 El Apoyo Provincial es un profesional de FOSIS, cuya misión es la de funcionar como enlace entre el equipo municipal y el equipo regional del programa Familias en FOSIS. Transmite las modificaciones metodológicas y realiza la supervisión del trabajo de las AFI en terreno. 
ayudas directas, para aliviar la situación crítica que enfrentaban las familias más vulnerables ante la emergencia sanitaria:

\begin{abstract}
"Mira nosotras, ahora en este momento estamos haciendo seguimiento telefónico con las familias [...] voy haciendo seguimiento, bueno en verdad, yo tengo mis carpetas de trabajo acá en la casa entonces, yo abro la carpeta, como que hago un poco de-, voy leyendo para recordar lo últimos que hablé con ella, y desde ahí como comenzar una conversación. Y ella, ahí voy, no sé poh, con algunas ni siquiera abro la carpeta en verdad. Pero solamente tomo por el lado de la situación en la que están, algunas están, saturadas ya en la casa, con el tema de los niños. O problemas económicos, han tenido no sé, algunas que, casi poco menos que ir a pedir a la calle, mercadería o ayuda, entonces como que ha sido mucha contención este tiempo con las familias. Entonces como que la sesión telefónica, se da entre seguimiento y contención" (Entrevista 14, AFI y GSC, municipalidad urbana)
\end{abstract}

En efecto, los relatos que apuntan hacia la necesidad de contención y de ayudas inmediatas son la gran mayoría. No obstante, debido a que el rol de las AFI en el programa Familias es únicamente derivar hacia otros servicios municipales o estatales, las profesionales se veían impedidas de garantizar una capacidad gestión y respuesta reales frente a las demandas de las familias usuarias. Aun evidenciando esta dislocación, desde las jefaturas municipales y desde FOSIS se continuó exigiendo la continuidad de la intervención. Para asegurar esto, se generaron nuevos mecanismos de control, en particular, la solicitud de remisión de planillas-semanales o diarias-, en donde las profesionales debían describir las tareas realizadas:

"es una planilla drive que hay que entregársela a la, a la persona de la municipalidad que es nuestra jefa de unidad, que se entrega diario, que es todos, todo lo que uno hace en el día. Por ejemplo, cuántos llamados uno hace, eh, si uno ingresa al sistema, uno tiene que anotarlo todo. Aparte, tenemos lo que es, otro sistema, que es un sistema remoto en el cual nosotros ingresamos todo lo que es los llamados a las familias. Pero que sea, por ejemplo, relacionado en el ámbito a ver el estado de ellas" (Entrevista 24, AFI, municipalidad urbana)

En suma, las profesionales municipales se ven enfrentadas a un nivel de exigencia alto y nuevo. Por un lado, deben adaptarse para continuar con la intervención propia del programa Familias pero de forma remota; y por otro, las familias, que ya estaban en un escenario de vulnerabilidad, se enfrentan a 
situaciones cada vez más complejas producto de la pandemia. Esto implica un alto nivel de tensión psicológico para las AFI, puesto que además de apoyar a las familias, deben soportan la carga personal de encontrarse inmersas en la crisis sanitaria:

"El nivel de exigencia es altísimo, y en ocasiones sentimos un poco, no de parte de nuestras jefaturas que han sido del municipio, para nada, de ahi hemos sentido bastante empatía. De donde sentimos un poco de, de no, no conectarse con lo que está pasando con nosotros también es de parte del ministerio. En ese sentido como que, no hay mucha consideración respecto a que el trabajo en la casa se hace mucho más difícil, cuando estás lidiando con una situación externa que puede tener como consecuencia la muerte. Eh, los temores asociados a eso, a un posible contagio, sumado a un colapso eminente del sistema de salud" (Entrevista 20, AFI, municipalidad urbana)

La pandemia de COVID19 desnudó muchas falencias estructurales de la sociedad chilena. Algunas de estas problemáticas se evidencian en los relatos de las AFI, especialmente cuando describen las condiciones en las que se encuentran las familias usuarias. Ante la imposibilidad de mantener los mecanismos de obtención de recursos por parte de gran parte de la población, y la baja capacidad del gobierno de generar políticas efectivas para asegurar un mínimo bienestar, quienes sufren más suelen ser los más pobres, los más vulnerables. Desde su posición, las profesionales del programa Familias trabajan cotidianamente con estas personas, y hacen lo posible por mejorar sus condiciones en el contexto de crisis sanitaria:

"El otro día pasé, porque andaba viendo a una señora y, porque yo trabajo con muchos block, con hartos departamentos acá en la comuna, sectores bien, bien vulnerables acá en la comuna, y veo que tienen lienzos así afuera, como pegados, pidiendo cooperación o agradeciendo la cooperación que les han entregado para poder cocinar. Entonces, realmente es muy fuerte, porque la gente ahora requiere lo básico. Que es comer, en este caso. O poder pagar sus cuentas más básicas. Satisfacer las necesidades primarias, más que otra cosa" (Entrevista 19, AFI, municipalidad urbana)

Sin embargo, como hemos relevado, la capacidad de incidencia efectiva de las Apoyos Familiares Integrales es baja, ya que solo están habilitadas para derivar hacia otras unidades municipales o entregar información sobre la postulación a bonos y ayudas del gobierno central. Lamentablemente, en muchas ocasiones estas políticas de emergencia funcionan de forma deficiente. Las AFI mencionan 
la existencia de una letra chica en las ayudas, por lo que estas medidas ni siquiera llegan a la totalidad de las familias usuarias del programa Familias, por definición las más vulnerables de Chile:

"se creen muchas cosas. Porque se hablan también muchas cosas. El tema de las prioridades, de los beneficios, el tema de la canasta familiar ¿cachai? Que en la tele dicen 'no, es que todas las familias tienen derecho'. O ahora, los mismos bonos de ingreso familiar de emergencia, o el bono COVID ¿cachai? Que son bien populares, porque, sale el presidente hablándolo así como ya la máxima solución, pero cuando te vas al detalle, eh, no todas las familias, por ejemplo de nosotros, recibieron esos ingresos éticos, familiares de emergencia. No todas las familias recibieron el bono COVID ¿cachai? ¿por qué? Porque cada, cada beneficio tiene una letra más chica" (Entrevista 24, AFI, municipalidad urbana)

Debido a estos problemas evidenciados en las estrategias gubernamentales de alcance nacional, fueron las municipalidades las principales instituciones a las que recurrió la población más necesitada. Ante la imposibilidad de las familias más vulnerables de mantener sus fuentes de trabajo e ingresos, aumentó de forma importante el nivel de solicitudes de ayudas directas hacia las instancias municipales. Sin embargo, en estos casos las AFI tampoco poseen la capacidad de asegurar una solución, debiendo remitirse a informar a las familias sobre las gestiones a realizar, las que además pueden resultar en beneficios insuficientes ante las necesidades de las usuarias:

"con toda esta situación, hay mucha gente que trabaja, por ejemplo, lo que es en feria de las pulgas, o por ejemplo gente que ha quedado sin, sin trabajo. Entonces, eh, ellas nos dicen 'señorita, es que no tengo pa' comer', y claro, lo único que uno le puede decir es 'vaya a la muni. Tenga en cuenta que la muni se va a demorar', y después ya nos empiezan a preguntar 'señorita ¿usted sabe cuándo nos van a entregar?' Entonces igual nosotros por ese lado, también, eh, nos da vergüenza poh. Porque además tampoco es una caja así como dijéramos, ya, se demoraron porque es una caja más o menos contundente. No. Es, una caja así como, que con suerte le puede alcanzar como pa' dos o tres días a una familia" (Entrevista 25, AFI, municipalidad urbana)

Como un esfuerzo desesperado por encontrar soluciones, hubo equipos del programa Familias que optaron por autogestionar algún tipo de ayuda a las familias, ante la imposibilidad de apelar a su vinculación institucional para 
asegurar la entrega de recursos a las familias en extrema necesidad. A través de la recaudación de fondos de sus propios bolsillos y de sus cercanos, realizaron entregas de canastas familiares a las usuarias más necesitadas:

"imagínate que nosotros llegamos, justo hace como dos semanas atrás más o menos, nos reunimos como equipo, o sea, todo a través de whatsapp, y llegamos a un acuerdo de que hicimos como una especie de campaña interna, con nuestros contactos, amigos, familias, y nosotros juntamos lucas como equipo, y formamos varias cajas, y se las hicimos entrega a nuestras familias. O sea, a los casos más críticos que teníamos" (Entrevista 19, AFI, municipalidad urbana)

Las medidas de confinamiento, distanciamiento social y las restricciones a la libre circulación, evidenciaron la debilidad de muchos de los mecanismos de superación de la pobreza que el propio programa Familias promueve, especialmente el emprendimiento a través del autoempleo. Ante las restricciones extraordinarias, la fragilidad de los microemprendimientos quedó manifiesta, dejando en críticas situaciones a las familias que dependen de estos:

"Si tú te das cuenta, hoy día con la pandemia, todos estos microemprendedores y todo de lo que se sostenían en Chile es tan efímero, es tan volátil ¿cachai? O sea la gente, es que de verdad que es, para mí es casi vulnerador que le pasen tres gambas ${ }^{11}$ a las familias y que con eso compran ropa y tengan que vender en la feria. O sea ¿de qué superación de la pobreza me estás hablando?" (Entrevista 22, AFI, municipalidad urbana)

Hasta aquí se ha descrito, a través de las palabras y relatos de las AFI, las diferentes adaptaciones metodológicas que experimentó el programa Familias ante el inesperado escenario de una pandemia global. Más allá de estas modificaciones, las profesionales de esta política pública se ven confrontadas a importantes tensiones en su quehacer laboral, ya que el drástico cambio de una intervención cara a cara hacia un acompañamiento remoto no implica una desconexión de las Apoyos Familiares Integrales respecto de las familias usuarias, sino que las vuelve a confrontar con su baja capacidad de incidencia para otorgar respuestas frente a la crisis sanitaria. Frente a esto, ofrecemos una interpretación teórica de esta problemática, siempre a partir de las críticas, cuestionamientos y frustraciones expresadas desde los equipos municipales.

$11 \$ 300.000$ pesos. Corresponde a los fondos Yo Emprendo Semilla que entrega FOSIS, con los cuales se busca potenciar el microemprendimiento en la población extremadamente vulnerable. 


\section{Conclusiones}

A modo de conclusión, es importante realizar una interpretación teórica de la situación que se ha descrito. El programa Familias, en tanto que principal política pública dirigida hacia la población más pobre en Chile, resulta ilustrativa respecto de la gubernamentalidad del Estado chileno, marcadamente neoliberal (Fuica, 2017; Ramos, 2016). Institucionalizado mediante la ley 20.595 (2012), su modelo de gestión e intervención sobre la población vulnerable no es fácilmente modificable, lo que podría explicar por qué la adaptación metodológica realizada por FOSIS es un cambio de soporte (de la visita a la llamada telefónica) antes que una adaptación a la realidad contingente a la que se enfrentan las familias usuarias. Esto dificulta que el programa Familias pueda transformarse en una plataforma útil para dar respuestas gubernamentales hacia la compleja realidad que enfrentan sus usuarias, y se mantenga más como un apoyo emocional y de orientación informativa antes que un mecanismo de incidencia directa para el mejoramiento de las condiciones vitales de las familias más vulnerables de Chile. En esta misma ley, queda establecido que las prestaciones del PF son un derecho para las familias usuarias, pero este derecho se agota en el vínculo establecido con la profesional y la vinculación preferente con otros organismos estatales (Larrañaga et al., 2014; Rojas, 2019). Es, por lo tanto, un derecho a ser derivadas antes que el aseguramiento de condiciones vitales mínimas.

Respecto de las Apoyos Familiares Integrales, la crisis sanitaria evidencia varias aristas que resultan problemáticas. En primer lugar, la modificación metodológica hacia un acompañamiento remoto, implicó el sostenimiento de la intervención pero en un formato totalmente ajeno, la llamada telefónica. Las condiciones laborales de las profesionales cambian radicalmente, ya que deben sostener la intervención desde sus hogares, se desdibujan los límites horarios de su trabajo y deben responder tanto a los nuevos mecanismos de control, como a las dudas de sus usuarias. A pesar del esfuerzo evidenciado por cumplir con este requerimiento, la crítica realidad de las familias deriva la intervención hacia la contención y la información respecto de potenciales ayudas, alejándose del trabajo sobre las dimensiones del bienestar propio de la metodología del PF. Sumado a lo anterior, durante los meses de marzo a junio de 2020, no existió entrega de insumos para la realización de la intervención remota (computadores, celulares o reembolso del gasto en llamadas), ni tampoco una preocupación efectiva por el bienestar físico y psicológico de los equipos municipales.

En términos profesionales, las AFI levantan un serio cuestionamiento respecto de su incapacidad para gestionar directamente los requerimientos de las familias y la continua necesidad de derivar, ya que su conocimiento y criterio quedan subsumidos a las decisiones que tomen otros organismos municipales o estatales. Profundizaba por la pandemia, la posición periférica de las Apoyos Familiares Integrales en el ordenamiento institucional, se releva como una seria dificultad al momento de entregar soluciones a la población necesitada. Desde 
la contratación a honorarios hasta la falta de recursos propios para movilizar, no existe una valoración real del conocimiento y capacidad de gestión de los equipos del programa Familias. Ni las municipalidades, ni FOSIS ni el MDS potencian la labor realizada a nivel cotidiano por estas profesionales. El convenio, modelo de gestión estatal de los programas sociales, queda retratado como un formato de relación que debilita a los equipos territoriales y los mantiene trabajando desde la inseguridad. A pesar de la inexistencia de una valoración estatal del conocimiento privilegiado respecto de la realidad de la población más vulnerable del país, esto no es impedimento para que las AFI evidencien la fragilidad de los mecanismos estatales para la superación de la pobreza ante la crisis sanitaria, tanto los contingentes (bonos de emergencia) como los propios del programa Familias (microemprendimiento). Asegurar la continuidad laboral y poner en valor el conocimiento de las AFI sería una forma de profundizar y mejorar la intervención de forma continua, aunque hacerlo implicaría una modificación legal mayor.

Finalmente, resulta importante destacar cómo, con la presencia de una gubernamentalidad neoliberal respecto de la vulnerabilidad, las salidas que resultan más efectivas terminan siendo los actos individuales y autogestionados por los equipos municipales, antes que los mecanismos institucionales. Esto va desde la sistematización y ordenamiento de la información realizado por las GSC hasta la entrega de canastas familiares bajo iniciativa privada de los equipos. Si bien extraordinarios, resulta conmovedor el esfuerzo y compromiso evidenciado por las profesionales municipales hacia las familias usuarias, exponiendo los límites de lo asistencial socializado (Rojas, 2019) como mecanismo para la superación de la pobreza establecido por el Estado de Chile. 


\section{Referencias bibliográficas}

Ballestín, B. \& Fàbregues, S. (2018). La práctica de la investigación cualitativa en Ciencias Sociales y de la Educación. Editorial UOC.

Castillo, E. \& Vásquez, M. L. (2003). El rigor metodológico en la investigación cualitativa. Colombia Médica, 34(3), 164-167. http://hdl.handle.net/11592/7268

Castro-Gómez, S. (2010). Historia de la gubernamentalidad. Razón de Estado, liberalismo y neoliberalismo en Michel Foucault. Siglo del Hombre.

Díaz de Rada, Á. (2011). El taller del etnógrafo. Materiales y herramientas de investigación en etnografía. Universidad Nacional de Educación a Distancia.

Foucault, M. (1990). Tecnologías del yo. Y otros textos afines. Paidós Ibérica.

Foucault, M. (2008). Seguridad, Territorio, Población. Curso del Collège de France (1977 - 1978). Akal.

Foucault, M. (2009). Nacimiento de la Biopolítica. Curso del Collège de France (1978 - 1979). Akal.

Fuica Rebolledo, I. F. (2017). Representaciones del Ingreso Ético Familiar: expresiones de la Gubernamentalidad chilena. Perifèria. Revista de recerca i formació en antropologia, 22(2), 48-66. http://doi.org/10.5565/rev/periferia.615

Fuica Rebolledo, I. F. \& Carrasco Henríquez, N. (2021). Acortando brechas en torno a las políticas públicas. El caso del "Programa Familias" en Chile. Runa, 42(1), 315-332. http://doi.org/10.34096/runa.v42i1.8299

Galasso, E. (2011). Alleviating extreme poverty in Chile: the short term effects of Chile Solidario. Estudios de economía, 38(1), 101-127. https://doi.org/10.4067/S0718-52862011000100005

Gupta, A. (2015). Fronteras borrosas: el discurso de la corrupción, la cultura de la política y el estado imaginado. En P. Abrams, A. Gupta, \& T. Mitchell (Eds.), Antropología del Estado (pp. 71-144). Fondo de Cultura Económica.

Illanes, M. A. (2007). Cuerpo y sangre de la política. La construcción histórica de las visitadoras sociales (1887-1940). LOM.

Irusta, A. (2014). El concepto de Gubernamentalidad, la economización de la política y el problema del estado en Michel Foucault. Philosophia, 74(2), 39-59. 
Larrañaga, O., Contreras, D. \& Cabezas, G. (2014). Políticas Contra la Pobreza: de Chile Solidario al Ingreso Ético Familiar. PNUD. https://www.latinamerica. undp.org/content/rblac/es/home/library/poverty/politicas-contra-lapobreza--de-chile-solidario-al-ingreso-etico.html

Latour, B. (2008). Reensamblar lo social: una introducción a la teoría del actor-red. Ediciones Manantial.

Ley 20.595 de 2012. Crea el Ingreso Ético Familiar que establece bonos y transferencias condicionadas para las familias de pobreza extrema y crea subsidio al empleo de la mujer. 11 de mayo de 2012. D.O. No. 40264.

Ministerio de Desarrollo Social. (2016). Claves del Proceso de Fortalecimiento del Subsistema Seguridades y Oportunidades. http://www.chileseguridadesyoportunidades.gob.cl/docs/Claves.pdf

Ministerio de Desarrollo Social. (2017). Informe de Desarrollo Social 2017. http://www.desarrollosocialyfamilia.gob.cl/pdf/upload/IDS2017.pdf

Okongwu, A. F. \& Mencher, J. P. (2000). The Anthropology of Public Policy: Shifting Terrains. Annual Review of Anthropology, 29, 107-124. https://doi.org/10.1146/annurev.anthro.29.1.107

Olavarría, M. (2007). Conceptos Básicos en el Análisis de Políticas Públicas. http://repositorio.uchile.cl/handle/2250/123548

Ramírez, M. C. (2010). Presentación. La antropología de La política pública. Antipoda, (10), 13-17. https://doi.org/10.7440/antipoda10.2010.02

Ramos Zincke, C. (2016). La producción de la pobreza como objeto de gobierno. Ediciones Universidad Alberto Hurtado.

Restrepo, A. M. (2010). Las políticas públicas como mecanismos de reproducción del Estado: una mirada desde la política pública de juventud de Bogotá. Antipoda, (10), 85-106. https://doi.org/10.7440/antipoda10.2010.05

Rojas, C. (2019). Ayudar a los pobres. Etnografía del Estado social y las prácticas de asistencia. Ediciones Universidad Alberto Hurtado.

Rose, N. \& Miller, P. (1992). Political power beyond the State: Problematics of government. British Journal of Sociology, 43(2), 173-205. http://doi.org/10.1111/j.1468-4446.2009.01247.x 
Ruiz Olabuénaga, J. I. (2007). Metodología de la Investigación Cualitativa. Universidad de Deusto.

Shore, C. (2010). La Antropología y el estudio de la política pública: reflexiones sobre la «formulación» de las políticas. Antipoda, Revista de Antropología y Arquelogía, (10), 21-49. https://doi.org/10.7440/antipoda10.2010.02

Shore, C. \& Wright, S. (1997). Policy. A new field of anthropology. En C. Shore \& S. Wright (Eds.), Anthropology of Policy. Critical perspectives on governance and power (pp. 9-39). Routledge.

Van Dijk, T. A. (2003). La multidisciplinareidad del análisis crítico del discurso: un alegato a favor de la diversidad. En R. Wodak \& M. Meyer (Eds.), Métodos de análisis crítico del discurso (pp. 143-177). Gedisa.

Vega, O. (2011). La Paradoja de la Política Social y el Programa Puente: Superación de la extrema pobreza o inclusión/exclusión social. Revista MAD, (15), 93-103. https://doi.org/10.5354/0718-0527.2006.14023

Velásquez Gavilanes, R. (2009). Hacia una nueva definición del concepto "política pública". Desafios, (20), 149-187. https://revistas.urosario.edu.co/index.php/ desafios/article/view/433/377

Wodak, R. (2003). De qué trata el análisis crítico del discurso (ACD). Resumen de su historia, sus conceptos fundamentales y sus desarrollos. En R. Wodak \& M. Meyer (Eds.), Métodos de análisis crítico del discurso (pp. 286). Gedisa. 


\section{Agradecimiento}

El autor agradece al Programa de Formación de Capital Humano Avanzado de ANID, Chile, que financia sus estudios doctorales a través de Becas Chile, folio 72190277.

Dirección de correspondencia:

Inti Fernando Fuica Rebolledo

Contacto: inti.fuica.rebolledo@gmail.com 